\title{
Interface para telecomunicação bidirecional não verbal em tempo real
}

\author{
Interface for nonverbal bidirectional real-time telecommunication
}

\author{
> Estevam Quintino Gomes Júnior \\ Universidade Federal de Minas Gerais, Brasil \\ estevamgomes@gmail.com
}

\author{
> Ana Paula Baltazar dos Santos \\ Universidade Federal de Minas Gerais, Brasil \\ baltazar.ana@gmail.com
}

\begin{abstract}
This paper presents the development of a telepresence interface intended to investigate the possibility of a "place" for remote meeting. The main goal is to create a shared realm making users act remotely to expand their senses of presence and belonging. By using spatialized sensors and actuators it is possible to transform a room in a telecommunication device. The interface does not seek to replace other telecommunication technologies but to create a new way for autonomous communication which might also complement the existent ones.
\end{abstract}

Keywords: Remote; Non-verbal communication; Presence; Telecommunication; Physical computing

\section{Introdução}

A necessidade de comunicação em tempo real entre espaços geograficamente distantes estimulou o desenvolvimento da telecomunicação. Inicialmente, as mensagens transmitidas consistiam em poucos sinais visuais ou sonoros, enviados isoladamente, com o significado estabelecido previamente pelas partes envolvidas. Um exemplo era a cadeia de torres de sinalização dispostas por toda a extensão da grande muralha da China (Sterling, 2008). Cada torre tinha tochas, tambores e bandeiras que poderiam ser acesas, tocados e hasteadas conforme a situação do inimigo. O sinal era replicado pelas torres adjacentes, sendo propagado por até 700 milhas (1120 $\mathrm{km}$ ) em um dia. Algumas tribos indígenas também usavam sinais de fumaça e sons tocados em tambores para se comunicar à distância.

Com o desenvolvimento da produção e transmissão da eletricidade foi criado o telégrafo, que permitia a transmissão de uma grande quantidade de símbolos em um curto período de tempo, possibilitando a transmissão de mensagens verbais através do código Morse. O telefone, criado algumas décadas depois, tornou a comunicação mais acessível já que não exigia do usuário o aprendizado de um novo alfabeto, o que enriqueceu a telecomunicaçáo pois, através da fala, possibilitou o uso da paralinguagem (e.g. uso da voz, entonação, ritmo). Ainda assim, há entre o telefone e a comunicação presencial um abismo pois, numa cultura baseada no visual "os gestos do homem visual não são feitos para transmitir conceitos que possam ser expressos em palavras, mas sim em experiências interiores, emoçóes não racionais que ficariam ainda sem expressão quando tudo o que pudesse ser dito fosse dito" (Balázs,
1983, p. 78). Segundo Ray Birdwhistell (apud Giri, 2009), cerca de $65 \%$ da comunicação humana ocorre por meio de gestos, postura, posição e distância e 35\% por meio de palavras. Para superar essas limitaçóes surgiram os primeiros equipamentos de videotelefonia, mas devido à sua complexidade e custo, a comunicação audiovisual só se popularizou com o desenvolvimento da internet.

Os softwares para videoconferência acrescentam à experiência do telefone a possibilidade de se expressar por meio de gestos e expressóes faciais (kinesia) mas ainda promovem uma experiência fragmentada da comunicação. Além disso, a comunicação possibilitada pela videoconferência ainda "se dá num "não-lugar", ou "lugar-nenhum”, já que cada pessoa está num espaço físico distinto e o ambiente digital não gera nenhuma ambientação de fato para o encontro" (Baltazar \& Costa, 2006b). Pesquisas sobre telepresença investigam meios para tornar a experiência de comunicação mais imersiva e criar um "lugar" para o encontro. A atuaçáo remota (e.g. robôs teleoperados), a transmissão em tempo-real de imagens estereoscópicas, e a criação de ambientes de imersão (e.g. Cave Automatic Virtual Environment), buscam ampliar a sensação de presença e pertencimento dos usuários baseando-se na representação realística do espaço (realidade virtual). No entanto, como já constatado por Baltazar et al (2014) as interfaces e os ambientes criados são apenas pobres imitaçôes da realidade e a presença não é explorada além das limitaçóes do espaço físico. O desenvolvimento de um meio para ampliar a sensação de presença usando as possibilidades oferecidas pela tecnologia da informação náo é discutida. Essas limitaçóes são sintetizadas na Tabela 1 que apresenta a relação entre os meios de 


\begin{tabular}{|c|c|c|c|c|c|c|c|}
\hline \multicolumn{2}{|c|}{ Tipo de comunicação } & \multirow[t]{2}{*}{$\begin{array}{l}\text { Sinais (tocha, } \\
\text { fumaça, tambor) }\end{array}$} & \multirow{2}{*}{$\begin{array}{c}\text { Telégrafo } \\
\mathrm{x} \\
\end{array}$} & \multirow{2}{*}{$\begin{array}{c}\text { Telefone } \\
\mathrm{x} \\
\end{array}$} & \multirow{2}{*}{$\begin{array}{c}\text { Videoconferência } \\
\mathrm{x} \\
\end{array}$} & \multirow{2}{*}{$\begin{array}{c}\text { Pesquisas de } \\
\text { telepresença } \\
\text { x } \\
\end{array}$} & \multirow{2}{*}{$\begin{array}{c}\text { Comunicação } \\
\text { presencial } \\
\text { x } \\
\end{array}$} \\
\hline Verbal & palavras & & & & & & \\
\hline \multirow[t]{7}{*}{ Não verbal } & sons & $\mathrm{x}$ & & $\mathrm{x}$ & $\mathrm{x}$ & $\mathrm{x}$ & $\mathrm{x}$ \\
\hline & imagens & $\mathrm{x}$ & & & $\mathrm{x}$ & $\mathrm{x}$ & $\mathrm{x}$ \\
\hline & paralinguagem & & & $\mathrm{x}$ & $\mathrm{x}$ & $\mathrm{x}$ & $\mathrm{x}$ \\
\hline & kinesia & & & & $\mathrm{x}$ & $\mathrm{x}$ & $\mathrm{x}$ \\
\hline & háptica & & & & & $\mathrm{x}$ & $\mathrm{x}$ \\
\hline & proxêmica & & & & & $\mathrm{x}$ & $\mathrm{x}$ \\
\hline & cheiro & & & & & & $\mathrm{x}$ \\
\hline
\end{tabular}

Tabela 1: Relação entre meios de comunicação e o tipo de comunicação proporcionado. As células preenchidas com "x" indicam que determinado meio possibilita o tal tipo de comunicação. As células em branco indicam que determinado meio não possibilita tal tipo de comunicação. Embora a "comunicação presencial" não seja um meio de comunicação ela foi usada como referência.

telecomunicação em tempo real e as formas de comunicação que eles proporcionam.

Para Merleau-Ponty (1983), a percepção não é a soma de dados visuais, táteis ou auditivos, a percepção é indivisível: "mediante meu ser total, capto uma estrutura única da coisa, uma maneira única de existir, que fala, simultaneamente, a todos os meus sentidos" (Merleau-Ponty, 1983, p. 105). A interface proposta parte de uma investigação sobre possibilidades de comunicação não fragmentada e ampliação das sensaçóes de presença e pertencimento criando um terceiro espaço que não seja somente físico ou digital. Para isso utiliza princípios da computação física e atuação remota para questionar a representação como principal meio de comunicação. A interface não busca substituir outros meios de telecomunicação, mas criar uma nova via de comunicação autônoma que possa ser também complementar a outros dispositivos.

\section{Articulação dos conceitos para a construção da interface}

O terceiro espaço é um híbrido do mundo físico e digital onde cria-se, a partir da espacialização da interface que conecta dois espaços remotos, uma sensação de pertencimento. A espacialização, possível pela natureza flexível da interface, estimula o uso do movimento e da atuação no ambiente remoto proporcionando um retorno do engajamento corporal na comunicação, esquecido pela telecomunicação.

Com a criação do terceiro espaço é possível explorar tanto a proxêmica quanto a troca de sensaçóes hápticas. A proxêmica é a relação espacial entre indivíduos durante o processo de comunicação. Ainda que sempre exista uma distância entre as pessoas, para a proxêmica o tipo de relaçáo e a intimidade entre as pessoas pode ser dividida em quatro categorias: distância pública, distância social, distância pessoal e distância íntima (Andersen, 2009). Tais categorias indicam o grau de engajamento subliminar dos usuários, o que pode ser estimulado pela criaçáo do terceiro espaço, promovendo uma ambientação para a comunicação. Um outro tipo de engajamento dos usuários se dá pela comunicação háptica (toque). Esta é uma das formas mais íntimas de comunicação, tendo grande importância na transmissão de afeto. A comunicação háptica remota foi tema da pesquisa de Jocelyn Smith e Karon MacLean (2007) e seus resultados indicam que não só é possível transmitir afeto através de uma ligação háptica como não há razão para acreditar que o toque seja menos importante que a visão. Por meio do toque remoto foi estabelecida cumplicidade entre os participantes, o que foi interpretado pelos pesquisadores como desenvolvimento de empatia. Tal cumplicidade ou empatia é crucial para ampliar as sensaçóes de presença e pertencimento. Além da ambiência para iniciar o engajamento dos usuários de forma subliminar, a interface pode também estimular uma atuação háptica remota. Em ambos os casos, o principal objetivo é ampliar a possibilidade de diálogo entre os usuários. Segundo Vilem Flusser (1999) todo projeto responsável é antes de tudo intersubjetivo, ou seja, é aberto ao outro estimulando o diálogo.

Outra característica importante no desenho da interface é a flexibilidade para se adaptar e transformar os ambientes onde é temporariamente instalada, assemelhando-se à TENDA Digital, proposta por Baltazar e Cabral Filho (2006a, p. 346): "baseando-se em uma compreensão mais generosa e rigorosa do espaço arquitetônico do que a idéia de um cômodo (room), a TENDA não pretende ser um cômodo dentro de outro cômodo como as CAVEs, mas sim pretende requalificar o ambiente onde ela se instala”.

Um último cuidado no desenho de tal interface é o de evitar que a complexidade dos mecanismos se sobreponha à experiência dos usuários, ou seja, a interface deve promover o que Baltazar e Cabral Filho (2011) chamam de magia da experiência, evitando que os usuários fiquem seduzidos pelo mero desconhecimento dos mecanismos operacionais, que quando revelados fazem com que a experiência perca sua relevância (magia da ignorância).

\section{Experimentos relacionados}

Algumas pesquisas recentes produziram interfaces que buscam explorar a comunicaçáo remota nấo visual. Huggy Pijama (Teh, 2008), desenvolvido pelo Mixed Reality Lab, é um sistema composto por um vestível e um urso de pelúcia que buscam transmistir remotamente a sensação de um abraço. O participante A pressiona um urso de pelúcia, sensores de pressão lêem os dados e as informaçôes são transmitidas pela internet para um casaco vestido pelo participante B. Este casaco contém bolsas de ar que inflam e pressionam a pele, esquentam e mudam de cor conforme a pressão. Esse dispositivo explora a comunicaçáo háptica podendo inclusive substituir outras formas de comunicação. Apesar de ser apontada a possibilidade de 
que ambos os participantes tenham um urso e um casaco, isso não seria suficiente para transformar a comunicação em um diálogo, a interface é essencialmente unidirecional. Pelo caráter funcional da interface a interação possível é previsível, abrindo pouco espaço para uma interação lúdica (Baltazar et al, 2014) em que usuários podem se apropriar do aparato além das suas prescriçóes, envolvendo-se com o conteúdo e não apenas com a interface.

Di-Dah-Dit (Visnjic, 2014) é um jogo telepresencial criado por Camille Morizot durante sua pesquisa de mestrado em Media Design na Haute école d'art et de design. Sáo dois dispositivos similares compostos por uma bola metálica apoiada em duas hastes móveis sobre uma tela de LEDs, situados em ambientes distintos. Ambos os dispositivos se comunicam remotamente e se completam, reproduzindo o movimento das hastes e da bola de um dispositivo no outro. Em cada ambiente o dispositivo aciona as hastes de duas maneiras. $\mathrm{O}$ usuário A no ambiente $\mathrm{A}$ aciona diretamente as hastes pelo lado A do dispositivo (o único disponível neste caso). O mesmo acontece no ambiente $\mathrm{B}$. A ação do usuário A é reproduzida remotamente no dispositivo $\mathrm{B}$, simulando a presença do lado $\mathrm{A}$ no dispositivo B. O mesmo acontece no dispositivo A. A bola se move nos dois dispositivos simultaneamente de acordo com a negociação remota dos dois usuários para a abertura das hastes em cada uma das extremidades. Quando as hastes estáo paralelas a bola fica parada, se as pontas se afastam em uma das extremidades a bola corre para este lado. A tela envia informaçóes para os jogadores propondo um objetivo para a negociação. Apesar do output para os jogadores ser predominantemente visual, há uma atuaçáo remota de fato na interface e o aspecto lúdico da interação cria uma experiência envolvente e comunicativa promovida pela negociação na ação (não verbal), além da abertura da interface que possibilita que os jogadores brinquem além da sua programação inicial.

Long Distance Voodoo (Baltazar et al., 2014), uma experiência realizada em 2011 pelo LAGEAR (Laboratório Gráfico para Experimentação Arquitetônica), promoveu uma conexão entre duas cidades, Berlim e Belo Horizonte. O projeto iniciou-se a partir de uma parceria com o grupo de dança contemporânea Contato Improvisação. Os dançarinos deste grupo iniciam seus movimento improvisados a partir do toque de outro dançarino. Assim, foi criada uma interface (Figura 1) que permite que pessoas em locais remotos possam interferir diretamente em um dançarino, e indiretamente em todo o conjunto, já que o movimento de um reverbera em todos os outros. A interface consiste em uma boneca com sensores de pressão localizados na cabeça, nos dois braços e nas duas pernas e um vestível com motores e LEDs localizados em lugares análogos aos sensores da boneca. A boneca foi dependurada em frente à um café em Berlim e o vestível usado por um dançarino em uma praça de Belo Horizonte. Além da conexão por meio dainterface os dois locais estavam conectados por uma videoconferência que possibilitava retorno visual. Quando um participante em Berlim tocava na boneca um sinal era enviado para o vestível em Belo Horizonte vibrando o motor correspondente e estimulando um movimento do dançarino.

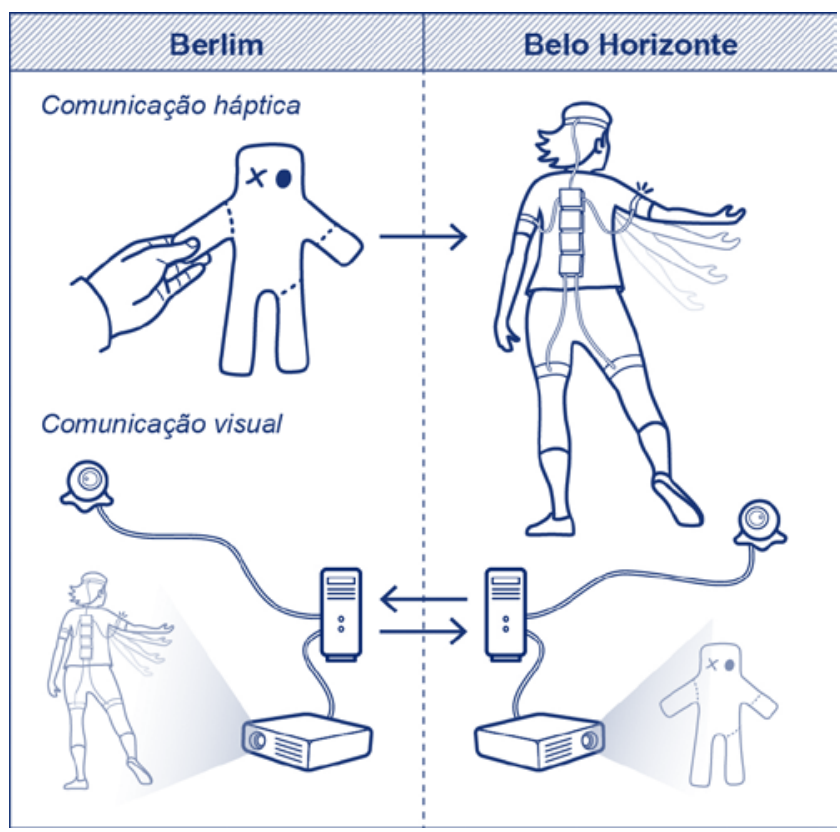

Figura 1: Esquema de funcionamento do Long Distance Voodoo. As setas indicam o fluxo de dados. A comunicaçâo háptica é unidirecional e a comunicação visual bidirecional.

Neste caso o delay entre a ação na boneca e a resposta do dançarino dificultou a negociação entre os dois espaços. Em Berlim, as pessoas estavam interessadas mais na mágica do toque remoto do que no diálogo possível. A posição estática da boneca dificultou o engajamento corporal e a necessidade de olhar a projeção para entender o que estava acontecendo no outro espaço e dar significado à própria ação reforçava a lógica visual. Contudo, a interface tátil explorou o sentimento de presença além da representação já que as pessoas estabeleceram uma conexão corporal através da atuação remota. A conexão disparou uma comunicação espacializada

Figura 2: Esquema de funcionamento da interface. As setas indicam o fluxo de informaçôes.

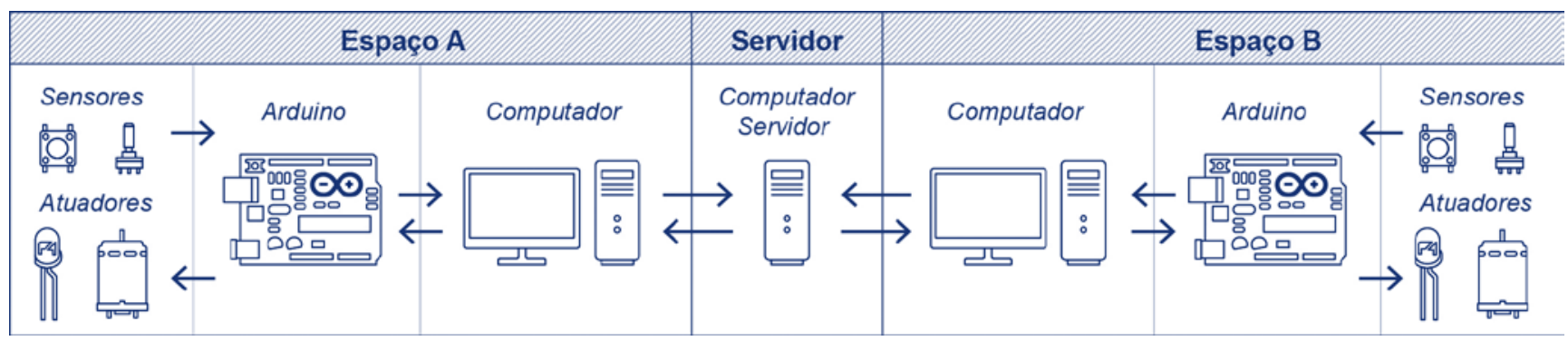


quando as pessoas gradualmente descobriam que poderiam tocar remotamente o dançarino iniciando uma interação mais durável e significativa já que o dançarino participava da conversa reagindo ao toque remoto influenciando o resto do grupo reverberando o estímulo recebido. O experimento conseguiu conectar dois espaços remotos com sucesso, apesar das dificuldades mencionadas.

\section{A interface}

Para investigar como a atuação remota e a espacialização da comunicação podem aumentar a sensação de presença e pertencimento e enriquecer a telecomunicação foi desenvolvida uma interface que tomou como ponto de partida a pesquisa do professor Sandro Canavezzi de Abreu, da Universidade Federal de Uberlândia, que idealizou um software para troca de dados entre sensores e atuadores localizados em espaços remotos. A partir desta ideia desenvolvemos nossa interface visando possibilitar a comunicaçáo náo verbal por meio da manipulação de atuadores remotos por sensores locais, que podem ser combinados livremente, sem um significado prescrito, cabendo aos usuários definirem o sentido de suas açóes. É possível mediar a comunicação, fazendo que a resposta (criada pela média dos sensores) seja a mesma nos dois espaços, estimulando os usuários a negociarem para chegar ao resultado que desejam. Como os sensores e atuadores são fisicamente independentes é possível espacializar a comunicação e adaptar a interface para ser instalada em diversos locais. Com a espacialização, o uso de inputs que demandam um engajamento corporal do usuário (sensor de presença e distância) e o uso de outputs que estimulam hapticamente (motores) e possibilitam a atuação remota é possível ir além do estímulo visual e ampliar a sensação de presença e pertencimento. Por fim, a interface procura estabelecer a cumplicidade entre os participantes por meio do diálogo e da negociação.

A interface conecta o espaço $A$ ao espaço $B$ através da mediaçáo de um servidor. Ao estimular sensores (e.g. potenciômetro) em um espaço, os dados sáo coletados pelo servidor, que os envia ao outro espaço, onde ocorre a decodificação e estímulo ao atuador (e.g. LED ou ventoinha) correspondente. Cada espaço recebe um kit (Figura 2) com um computador, um microcontrolador Arduino e uma conjunto de sensores e atuadores. Os sensores e atuadores são divididos em dois grupos, analógicos e digitais. Os sensores analógicos são os sensores capazes de fazer leituras que variam dentro de uma determinada extensão como o sensor de rotaçâo (potenciômetro), o sensor de pressáo e o sensor de luz (LDR). Os sensores digitais são aqueles capazes de fazer leituras binárias como o push-button e o sensor de presença. Os atuadores analógicos são os atuadores que variam de intensidade dentro de uma determina extensão como motor DC, LED, o motor de vibração e o buzzer. Os atuadores digitais são aqueles que têm apenas dois estados, ligado ou desligado, como o relé. Alguns motores DC são mistos já que é possível controlar a direçáo com um input digital e a velocidade com um input analógico.

Cada Arduino está programado para manipular até seis sensores analógicos, seis atuadores analógicos, três sensores digitais e três atuadores digitais. O programa trabalha com a correspondência direta, ou seja, cada sensor no espaço A tem um atuador correspondente

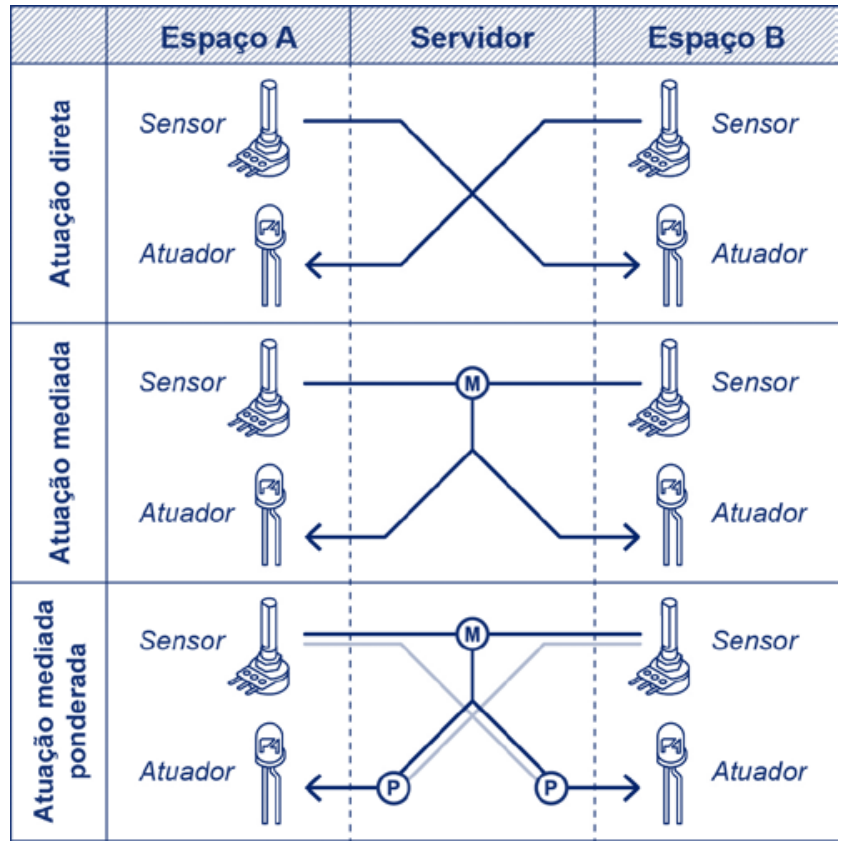

Figura 3: Esquema das possibilidade de mediação pelo servidor. O M significa a média e o $\mathrm{P}$ a ponderaçấo realizada.

no espaço $B$ e vice-versa. Por exemplo, ao girar um potenciômetro no espaço A, conectado à entrada analógica 01 , este sinal é lido pelo Arduino, enviado ao computador através da porta serial, recebido pelo software desenvolvido no Processing e enviado ao servidor. Simultaneamente o software no espaço B lê os dados enviados pelo servidor e os encaminha ao Arduino que decodifica e altera a velocidade de giro de um motor conectado à saída analógica 01 .

Apesar da conexão direta entre os dois espaços ser possível, o uso do servidor tem algumas vantagens como: a simplificaçâo do processo de instalaçáa removendo a necessidade de configurar o roteador da rede local, essencial para um dispositivo que proponha uma instalação efêmera e deseje ser flexível; e permitir a experimentação de outras formas de conexão através da mediação e tratamento dos dados. Como mostrado na Figura 03, a influência do servidor pode acontecer de três formas: a atuação direta, onde o servidor não interfere nos dados enviados e cada sensor está ligado diretamente a um atuador no espaço remoto; a atuação mediada, onde o servidor recebe os dados de ambos os lugares, e envia a média aos dois espaços estimulando igualmente os atuadores; e a atuação mediada ponderada, onde, após a operação dos dados, o servidor envia uma média ponderada aos dois espaços, sendo que os atuadores teráo uma resposta diferente mas o usuário terá um feedback da sua ação. A conexão também pode ser mista, sendo mediada para alguns sensores e direta para outros, podendo usar os sensores e atuadores mediados para criar uma ambiência comum e a conexão direta para a atuação remota.

Foram realizados testes conectando duas salas da Escola de Arquitetura da UFMG através da internet. O servidor foi instalado em um computador do LAGEAR que tem acesso direto à internet utilizando um IP fixo e os clientes foram conectados à internet através das redes internas da sala onde estavam instalados. O programa desenvolvido 
conseguiu enviar os dados com sucesso à uma taxa de atualizaçáo de $30 \mathrm{fps}$, adequada para uma comunicação em tempo real. Os sensores (potenciômetro, push-button e LDR) foram conectados diretamente (sem a mediaçáo do servidor) aos atuadores (motores DC e LEDs).

\section{Conclusão}

Com o uso de tecnologias difundidas e hardware off-the-shelf foi possível desenvolver um sistema para telecomunicação bidirecional interpessoal não verbal em tempo real. Apesar de poucos testes realizados é possível concluir que a interface teve sucesso tecnicamente, embora não seja possível mensurar a qualidade da comunicação em relação a outros dispositivos. Possíveis avanços poderiam ser feitos ampliando a gama de sensores e atuadores usados e desenvolvendo um método para testar suas diferentes combinaçóes avaliando sua contribuição individual para a comunicação. $\mathrm{O}$ desenvolvimento deve focar em proporcionar o diálogo e o engajamento corporal ao invés de criar uma experiência contemplativa e visual (magia da ignorância). A interface deve se manter aberta o suficiente para não limitar a comunicação e suas regras devem ser criadas para melhorar a experiência sem prescrever as açôes. Para isso os "objetos" sensores e atuadores devem ser criados visando ampliar as possibilidades de comunicação dialógica por meio da negociaçáo e da cumplicidade em interaçóes lúdicas e na atuação remota, proporcionando uma sensação de presença e pertencimento.

\section{Agradecimentos}

Os autores gostariam de agradecer as agências de fomento FINEP, CAPES, CNPq, Fapemig e Pró-Reitoria de Graduação da UFMG. Agradecem também ao professor e pesquisador Sandro Canavezzi e ao LAGEAR UFMG.

\section{References}

Andersen, P. A. (2009). Nonverbal Communication Theories. In S. W. Littlejohn, \& K. A. Foss (Eds.), Encyclopedia of Communication Theory (pp. 807-808). Thousand Oaks, CA: SAGE Publications.

Balázs, B. (1983). O homem visível. In I. Xavier (Ed.), A Experiência do Cinema: Antologia (pp. 77-83). Rio de Janeiro: Ediçóes Graal.

Baltazar, A. P., \& Cabral Filho, J. S. (2006a). Tenda Digital/Digital TENT (Technological Environment for Negotiated Topology) e suas possíveis implicaçóes em contextos sociais. In X SIGRADI Congreso Iberoamericano de Gráfica Digital, 2006, Santiago. (pp. 346-349). Santiago: Universidad de Chile.

Baltazar, A. P., \& Costa, R. (2006b). O espaço como evento. Versão completa da entrevista concedida por Ana Paula Baltazar à Raquel Costa em ocasião do Projeto Ocupar Espaços da ONG Oficina de Imagens. Retrieved from http://www.mom.arq. ufmg. br/lagear/?page_id=384

Baltazar, A. P., Cabral Filho, J. S., Arruda, G., Melgaço, L., \& Almeida, M. (2014). Beyond the visual in urban interactive interfaces: dialogue and social transformation. International Journal of Creative Interfaces and Computer Graphics. (no prelo)

Baltazar, A. P., Cabral Filho, J. S. (2011). Magia além da ignorância: virtualizando a caixa preta. In Roscoe, Henrique, Moran, Patrícia \& Mucelli, Tadeus (Eds.), FAD - Festival de Arte Digital 2010 (pp. 12-18). Belo Horizonte: Instituto Cidades Criativas.

Flusser, V. (1999). Design: obstacle for/to the removal of obstacles. In Flusser, V. The shape of things: a philosophy of design (pp. 51-62). London: Reaktion.

Giri, V. N. (2009). Nonverbal Communication Theories. In S. W. Littlejohn, \& K. A. Foss (Eds.), Encyclopedia of Communication Theory (pp. 690-694). Thousand Oaks, CA: SAGE Publications.

Merleau-Ponty, M. (1983). O cinema e a nova psicologia. In I. Xavier (Ed.), A Experiência do cinema: antologia (pp. 103117). Rio de Janeiro, RJ: Ediçóes Graal.

Smith, J., \& MacLean, K. (2007). Communicating emotion through a haptic link: Design space and methodology. International Journal of Human-Computer Studies, 65(4), 376-387.

Sterling, C. H. (2008). Great Wall of China. In Sterling, C. H. (Ed.), Military communications: from ancient times to the 21st century (pp. 197-198). Santa Barbara, CA: ABC-CLIO.

Teh, J. K. S., Cheok, A. D., Peiris, R. L., Choi, Y., Thuong, V., \& Lai, S. (2008). Huggy Pajama: a mobile parent and child hugging communication system. In Proceedings of the 7th international conference on Interaction design and children (pp. 250-257). ACM.

Visnjic, F. (2014). Di-Dah-Dit: A telepresence device by Camille Morizot. (n.d.) Retrieved from http://www.creativeapplications. net/arduino- 2/di-dah-dit-a-telepresence-device-bycamille-mo rizot/ 